TAO, Vol. 15, No. 3, 397-412, September 2004

\title{
Atmospheric Field Variations before the March 31, 2002 M6.8 Earthquake in Taiwan
}

\author{
Masashi Kamogawa ${ }^{1, *}$, Jann-Yenq Liu ${ }^{2}$, Hironobu Fujiwara ${ }^{3}$, Yu-Jung Chuo ${ }^{4}$, Yi-Ben Tsai ${ }^{5}$, \\ Katsumi Hattori ${ }^{6}$, Toshiyasu Nagao $^{7}$, Seiya Uyeda ${ }^{7}$, and Yoshi-Hiko Ohtsuki ${ }^{3}$
}

(Manuscript received 14 April 2004, in final form 2 July 2004)

\begin{abstract}
Atmospheric electric field (AEF) observations and other concurrent measurements have been carried out in Taiwan over a three-year period in the context of seismo-electromagnetic studies. Generally, AEF variations appear to be due to meteorological effects. However, there seems to have been a correlation between AEF and the largest M6.8 earthquake on 31 March, 2002.
\end{abstract}

(Key words: Atmospheric electric field, Earthquake, Corona discharge, Ionospheric anomaly)

\section{INTRODUCTION}

Studies of seismo-electromagnetics have evolved over a few decades [See papers listed in Uyeda and Park (Eds.) 2002]. It has been reported that the phenomena appeared in wide frequency bands ranging from DC and ULF to VHF. In an atmospheric electric field (AEF) observation, Kondo (1968) measured the AEF with a field mill during the Matsushiro earthquake swarm in Japan, and reported that the intensity of the AEF slightly decreased (about 10-

${ }^{1}$ Department of Physics, Tokyo Gakugei University, Tokyo, Japan

2 Institute of Space Science, National Central University, Chung-Li, Taiwan

3 Department of Physics, Waseda University, Tokyo, Japan

4 Department of Information Management, Ling-Tung College, Tai-Chung, Taiwan

5 Department of Earth Sciences, Institute of Geophysics, National Central University, Chung-Li, Taiwan

${ }^{6}$ Marine Biosystems Research Center, Chiba University, Chiba, Japan

7 Earthquake Prediction Research Center, Tokai University, Shizuoka-shi, Japan

* Corresponding author address: Dr. Masashi Kamogawa, Department of Physics, Tokyo Gakugei University, 4-1-1 Nukuikitamachi, Koganei-shi, Tokyo, Japan; E-mail: kamogawa@u-gakugei.ac.jp 
$20 \%$ ) at the time of $60 \%$ earthquakes. Ikeya and Matsumoto (1997) and Ikeya et al. (1998), based on their laboratory experiments, suggested that some eyewitness reports of earthquakerelated macroscopic anomalies could be explained as being caused by AEF variations. Thus, several reports have implied the existence of large AEF variations before earthquakes. However, there have been no practical AEF observation associated with large earthquakes.

In the present study, AEF observations have been made during earthquake occurrences in Taiwan. Furthermore, the AEF variations are compared with other concurrently recorded data like seismicity, ultra lower frequency (ULF) magnetic variations, and GPS ionospheric total electron contents (TEC).

\section{OBSERVATION}

In order to measure AEF variations, several instruments have been used such as field mills, corona current meters, and capacitance meters (See Macgorman and Rust 1998). To establish a relationship with large earthquakes, recognizing AEF variations generally requires a long observation period. Consequently, durable and low-maintenance instruments are desired to keep a long-term record under the severe weather conditions such as strong typhoons and frequent lightnings in the Taiwan area. Corona current measurements are considered suitable under the ambient observation conditions.

Corona current measurements are based on the following physical principle. When there are electric charges on the surface of a semi-infinite metal plate facing a pointed metallic object (needle), corona discharges occur around the tip of the needle because the electric field around it is much higher than the ambient electric field. The current passing through the needle, called "corona current", can be measured and the amplitude of the ambient electric field can be obtained. The corona current $I$ caused by the ambient electric field $E$ is generally given by

$$
I=\left\{\begin{array}{cc}
a\left(E^{2}-M^{2}\right) & (E \geq M) \\
0 & (E<M),
\end{array}\right.
$$

where $a$ and $M$ are constants that depend on the shape of the needle, height of its tip and so on (Chalmers 1967). Equation (1) shows that a corona current can be produced only when the electric field exceeds a certain value $M$. In the present observation, a commercial probe primarily developed for a lightning warning system was deployed as shown in Fig. 1a. The lightning prediction performance with this corona probe has been investigated (Kitagawa and Katoh 1995). A laboratory experiment has been done to obtain the constants for equation (1). For instance, at $1.35 \mathrm{~m}$ height of the probe, the following values were obtained: $a=3.9 \times 10^{-12}$, $M=11.98 \mathrm{kV} \mathrm{m}^{-1}$ when the electric field was directed from top to bottom, and $a=3.0 \times 10^{-12}$, $M=18.35 \mathrm{kV} \mathrm{m}^{-1}$ (electric field directed from bottom to top.). The direction of the corona current is defined as depicted in Fig. $1 b$.

So far, five observation stations have been installed in Taiwan as shown in Fig. 2. Note that probe height is approximately 8 meters (See Fig. 1a) to obtain sensitivity higher than at 
(a)

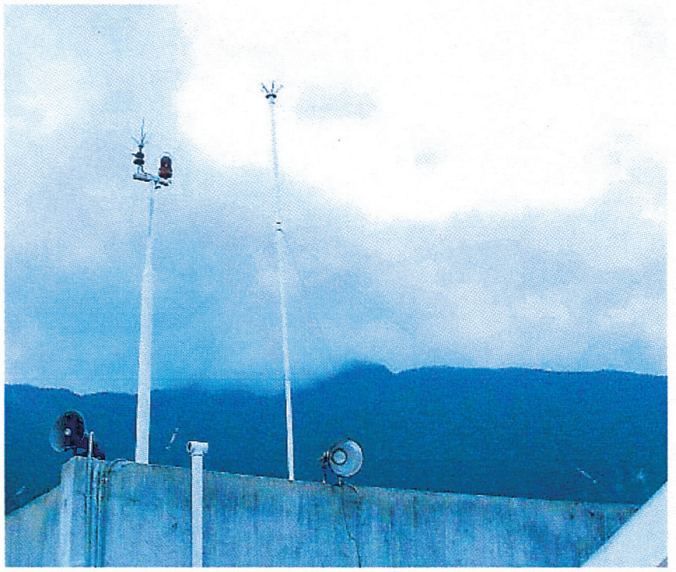

(b)

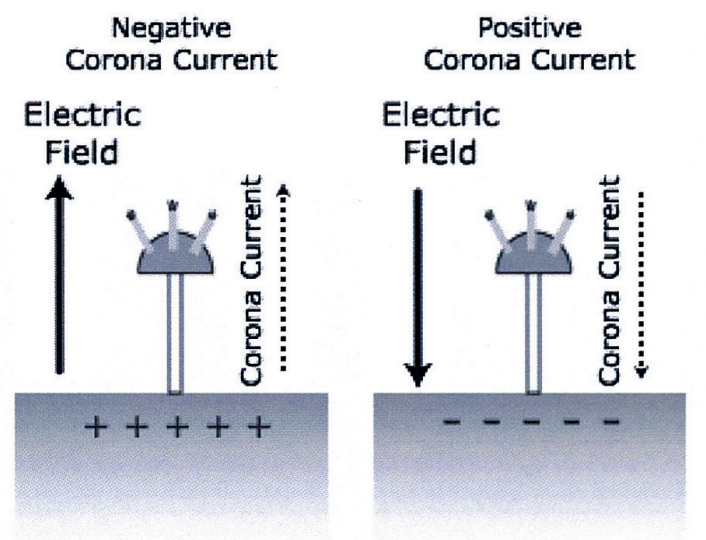

Fig. 1. (a) Corona probe at the Hualien station. The probe height is $8 \mathrm{~m}$ from the roof of the building. (b) Directions of corona current. As depicted here, the polarity of ground charge is obtained through the observed corona current direction.

the laboratory experiment. During the first 3-year observation period, only the station at Hualien $\left(\mathrm{E} 121.607^{\circ}, \mathrm{N} 24.040^{\circ}\right)$ was working relatively well. Thus, in the present study, only data from Hualien will be discussed.

Typical signatures caused by lightning activity and by rainfall are shown in Figs. 3 and 4 . In Fig. 3, examples of variations due to thunderclouds, cloud-to-ground lightning, and intracloud lightning are shown. A gradual change of the corona current indicates the approach and growing of a thundercloud. Sudden changes with the same polarity and across the zero indicate intra-cloud and cloud-to-ground lightning, respectively. Precipitation also causes AEF variations (See Macgorman and Rust 1998). Typical signatures of both positive and negative currents during rainfall are shown in Fig. 4.

Under the fair weather conditions AEF exhibits daily variations up to a few hundred $\mathrm{V} \mathrm{m}^{-1}$ (See Macgorman and Rust 1998). The corona current data of all five stations sometimes showed part of the daily variations when they exceeded the threshold value $M$. Therefore, the threshold $M$ is estimated to be around a few hundred $\mathrm{V} \mathrm{m}^{-1}$.

\section{RESULTS AND DISCUSSIONS}

In the present study, the observation period is from August, 2000 to July, 2003. During this period, ten $M \geq 5.5$ earthquakes occurred within $80 \mathrm{~km}$ of epicentral distance from Hualien with a focal depth less than $50 \mathrm{~km}$, including the largest $M 6.8$ earthquake as shown in Fig. 2 


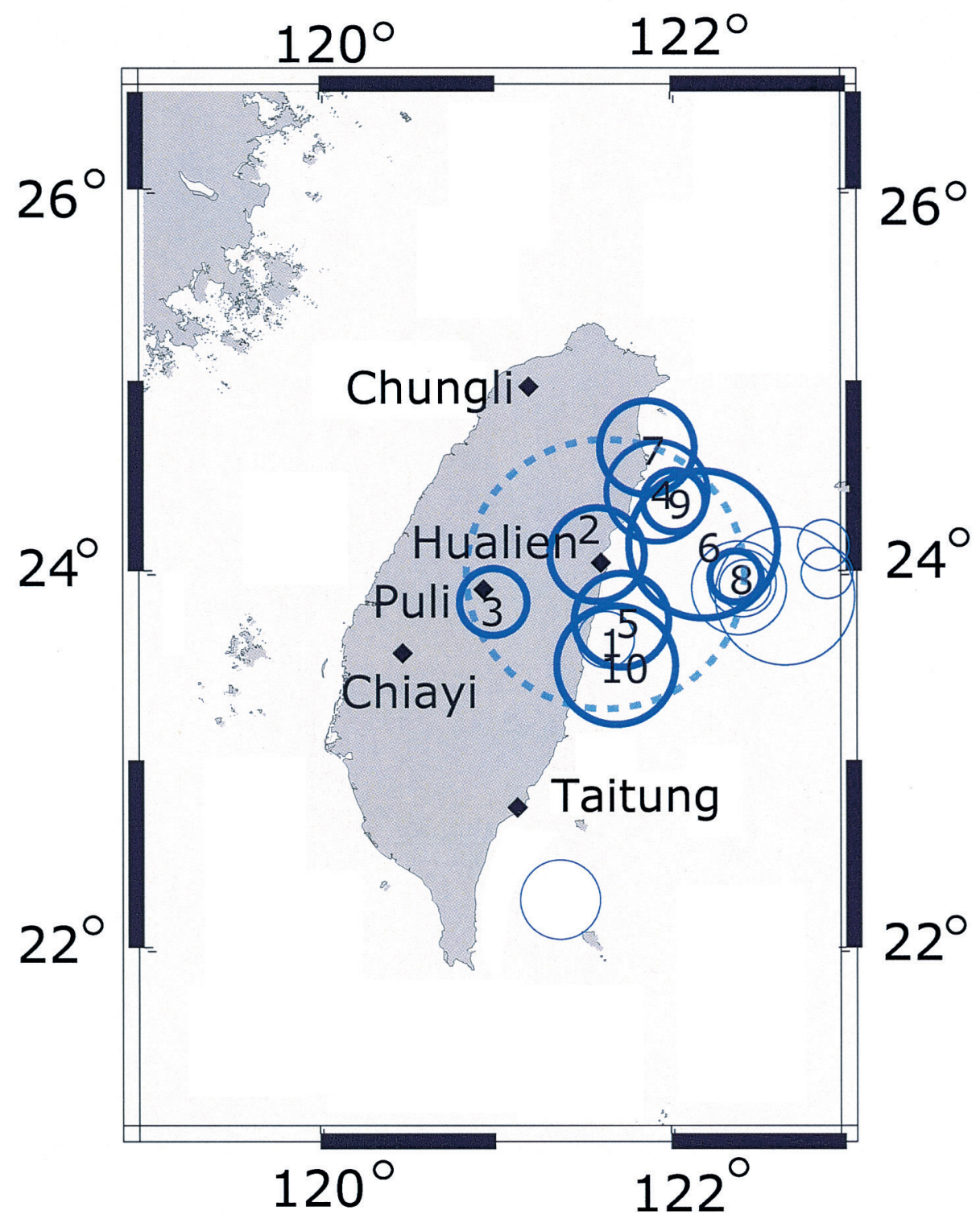

Fig. 2. Five observation stations: Chungli (E121.195, $\left.\mathrm{N} 24.968^{\circ}\right)$, Chiayi $\left(\right.$ E120.473 $\left.{ }^{\circ}, \mathrm{N}_{23.563^{\circ}}\right)$, Hualien $\left(\mathrm{E} 121.607^{\circ}, \mathrm{N} 24.040^{\circ}\right)$, Puli (E120.936 ${ }^{\circ}$, $\left.\mathrm{N} 23.900^{\circ}\right)$, and Taitung $\left(\mathrm{E} 121.127^{\circ}, \mathrm{N} 22.749^{\circ}\right)$. Open circles indicate $M \geq 5.5$ earthquakes during the 3 -year observation period. The geomagnetic station is located in Chiayi. Dotted circle presents $80 \mathrm{~km}$ radius from Hualien station. Numbers represent earthquakes listed in Table 1. 


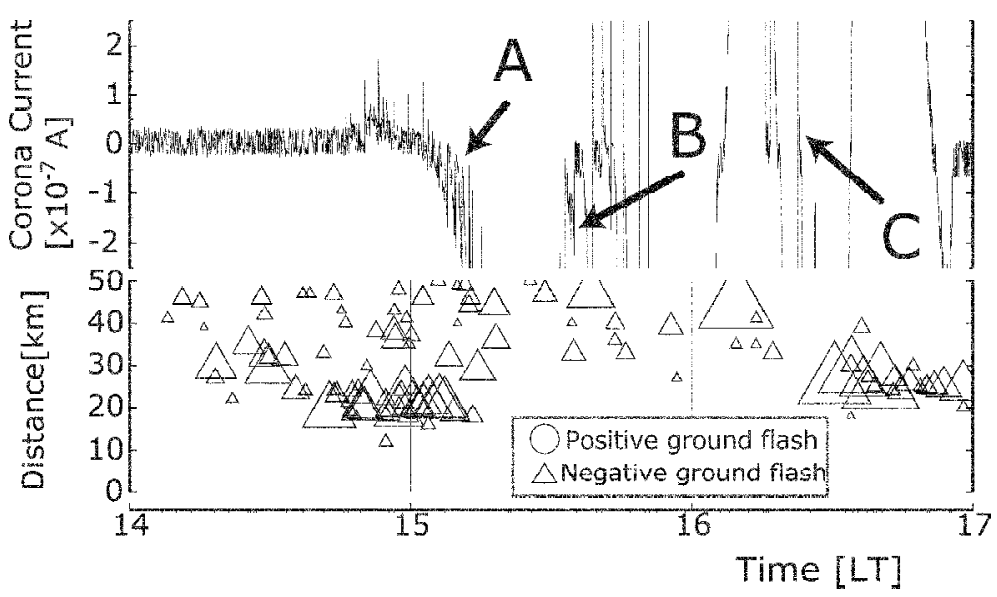

Fig. 3. Corona current of lightning activity at Hualien, showing charging due to the approach of a thundercloud (A), intra-cloud lightning (B), and cloudto-ground lightning (C) (June 9, 2001). Data of Cloud-to-ground lightning from Hualien is also shown(Taiwan Electric Power Company).

(a)

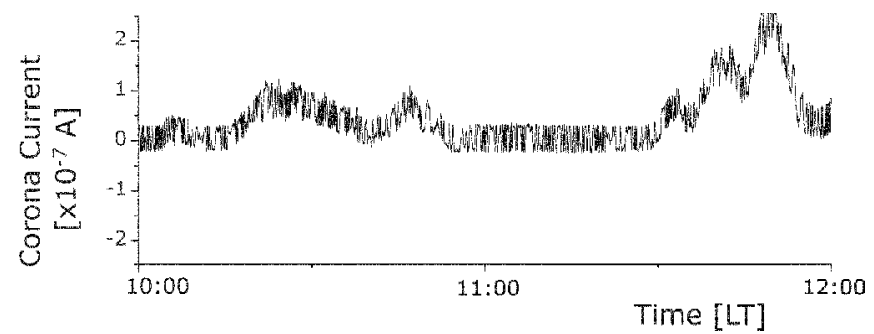

(b)

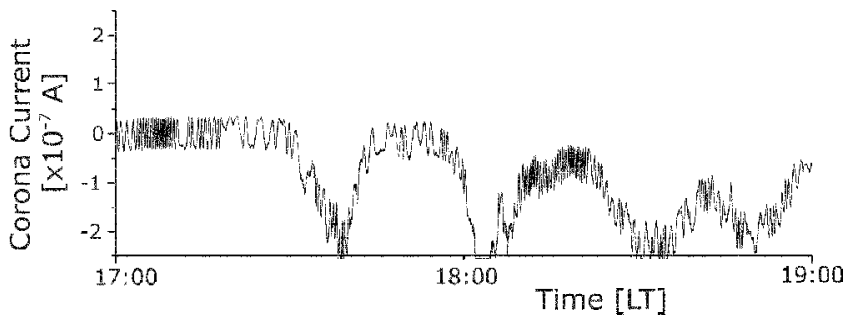

Fig. 4. Corona current variations caused by rainfall. (a) Positive corona current (January 28, 2002), when ground-based rainfall (Central Weather Bureau) was $1.0 \mathrm{~mm}$ (10:00-12:00 LT). (b) Negative corona current (August 2, 2002), when ground-based rainfall (Central Weather Bureau) was 10.0 $\mathrm{mm}$ (17:00-18:00 LT) and 0.5 mm (18:00-19:00 LT). 
and listed in Table 1. The M6.8 earthquake that occurred at 14:52:40 (LT) on March 31, 2002 killed five people and caused serious damage (See Fig. 5). AEF variations that differed from the general meteorological signature appeared two days before and one day before the main shock as shown in Fig. 6. In particular, the polarity of the corona current changed from positive (corresponding to the appearance of negatively charged area on the ground surface) to negative at the time of the main shock. Therefore, such variations might be the candidates of earthquake-related anomaly. During five of ten $M \geq 5.5$ earthquakes, Hualien data was recorded. AFE variations similar to those shown in Fig. 6 appeared within 4 days before these five earthquakes as listed in Table 1.

In any study of the seismo-electromagnetics observation, it is extremely difficult to prove that a pre-seismic anomaly is truly precursory and not coincidental. Therefore, it is important to collect other concurrent observations on each earthquake. A positive correlation would confirm a given mechanism and help in the development for future modeling. The following concurrent observations were carried out.

Table 1. Earthquake catalog* during observation period.

\begin{tabular}{ccccccccc}
\hline No & Date & Time(LT) & Lat. & Lon. & Dept. & Mag. & Epi. Dist. & AFE Variation \\
\hline 1 & $2000 / 8 / 23$ & $8: 49$ & E23.6 & N121.6 & $27.5 \mathrm{~km}$ & 5.6 & $45 \mathrm{~km}$ & $2000 / 8 / 22$ \\
2 & $2000 / 9 / 10$ & $16: 54$ & E24.0 & N121.5 & $17.7 \mathrm{~km}$ & 6.2 & $5 \mathrm{~km}$ & No data \\
3 & $2001 / 3 / 2$ & $0: 37$ & E23.8 & N120.9 & $10.9 \mathrm{~km}$ & 5.8 & $67 \mathrm{~km}$ & No data \\
4 & $2001 / 6 / 14$ & $10: 35$ & E24.4 & N121.9 & $17.3 \mathrm{~km}$ & 6.3 & $52 \mathrm{~km}$ & $2002 / 6 / 14$ \\
5 & $2002 / 2 / 12$ & $11: 27$ & E23.7 & N121.7 & $30.0 \mathrm{~km}$ & 6.2 & $35 \mathrm{~km}$ & No data \\
6 & $2002 / 3 / 31$ & $14: 52$ & E24.1 & N122.1 & $13.8 \mathrm{~km}$ & 6.8 & $60 \mathrm{~km}$ & $2002 / 3 / 30,3 / 31$ \\
7 & $2002 / 5 / 15$ & $11: 46$ & E24.6 & N121.8 & $8.5 \mathrm{~km}$ & 6.2 & $73 \mathrm{~km}$ & $2002 / 5 / 11$ \\
8 & $2002 / 9 / 1$ & $15: 07$ & E23.9 & N122.3 & $15.6 \mathrm{~km}$ & 5.5 & $78 \mathrm{~km}$ & No data \\
9 & $2003 / 6 / 9$ & $9: 52$ & E24.3 & N122.0 & $23.2 \mathrm{~km}$ & 5.7 & $55 \mathrm{~km}$ & $2002 / 6 / 8$ \\
10 & $2003 / 6 / 10$ & $16: 40$ & E23.5 & N121.6 & $32.3 \mathrm{~km}$ & 6.5 & $60 \mathrm{~km}$ & $2002 / 6 / 8$ \\
\hline
\end{tabular}

* Earthquake catalog: Central Weather Bureau, Taiwan

\subsection{Microfracture and Charging}

According to laboratory experiments carried out by Freund (1999), when rock cylinders are mechanically shocked, a positive charge propagated through the rock and appeared on the opposite side. This observation is consistent with the activation of mobile positively charged holes through shock - produced stress. The results also point to the possibility that microfractures during preparing stage of the main shock could excite the positive holes and that the holes would propagate through the ground. Moreover, the process might lead to a positively charged area on the ground when the positive holes reach the surface.

From the corona current direction, it was recognized that the charges on the ground surface during the M6.8 EQ-related variations had both polarities. In particular, the ground charge 
within 45 minutes before the main shock was negative that was opposite charge of Freund's proposal. Although the detectable magnitude of seismometers in Taiwan is 2.0 and might be not enough to monitor the microfractures, the seismicity during first and second variations on March 30 and 31, 2002 was investigated. There was no $M \geq 2$ seismicity during the variations as shown in Fig. 7.

(a)

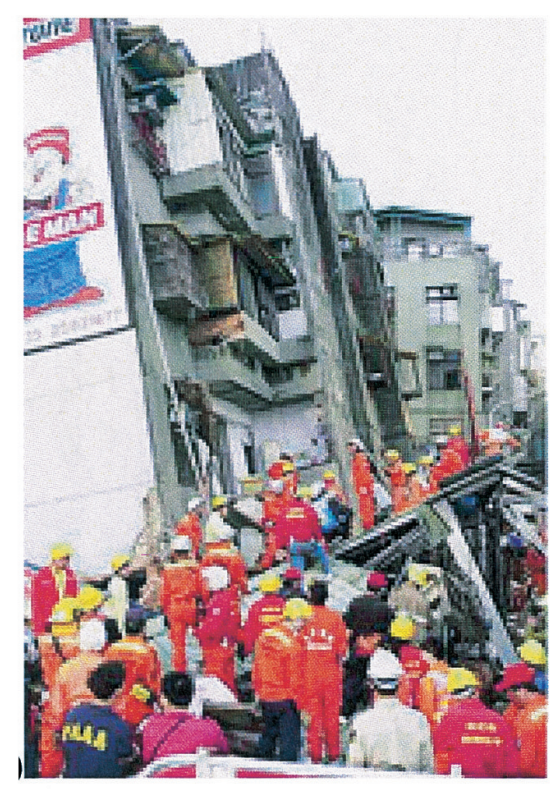

(b)

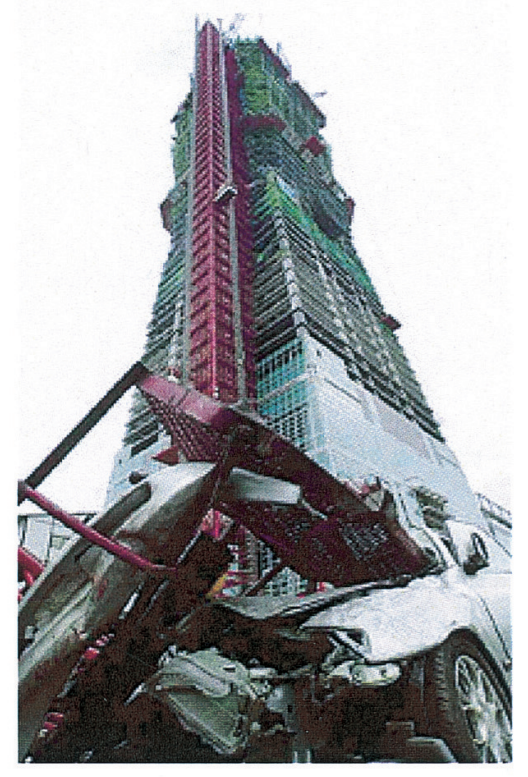

(c)

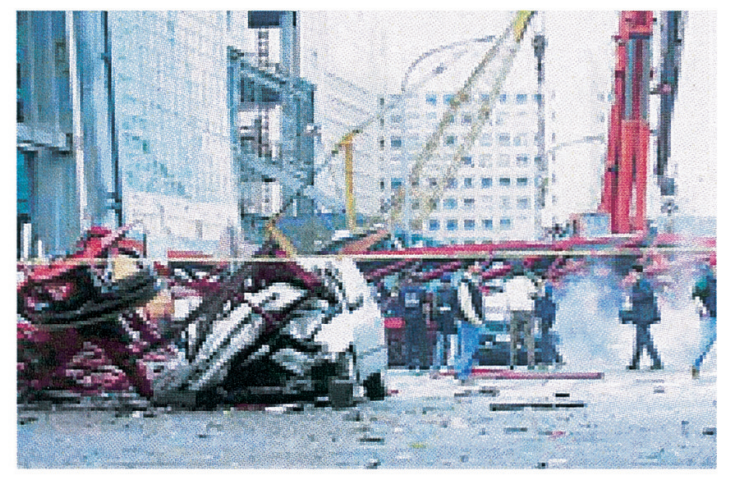

Fig. 5. M6.8 earthquake disaster on March 31 of 2002 in Taipei city $(150 \mathrm{~km}$ epicentral distance). (a) A 5-story building inclined. (b) Beam dropped from the building under construction. (b) The dropped beam hit the car. [After China times (newspaper) with their permission.] 
(a)

Day

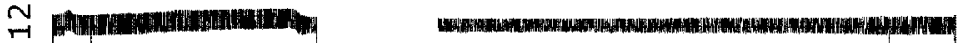

ๆ

I

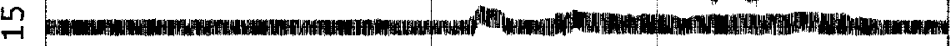

가

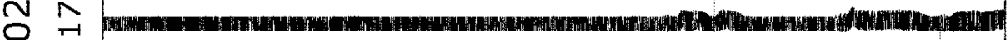

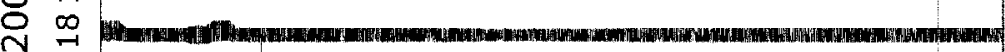

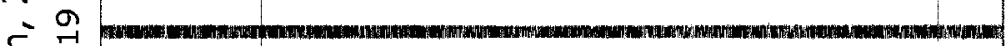

두의

$\frac{1}{\sigma} \mathrm{V}$.

$\sum$ 근.

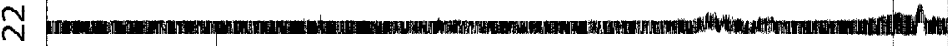

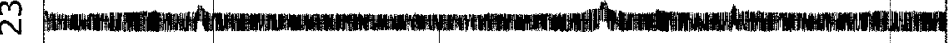

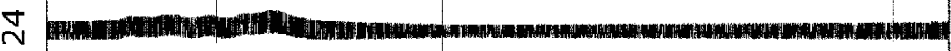

บn Wh

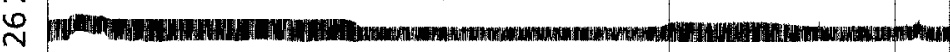

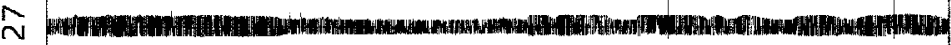

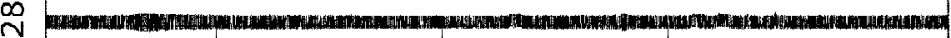

Y \

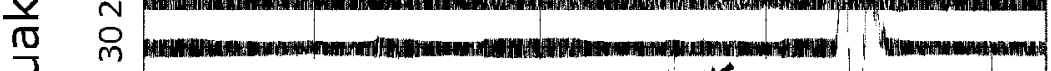

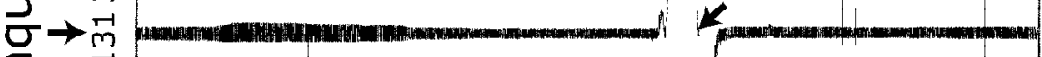

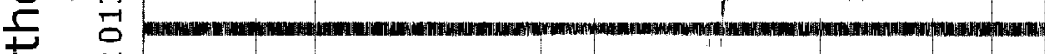

N

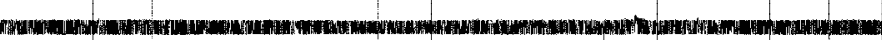

$M$ w.

す

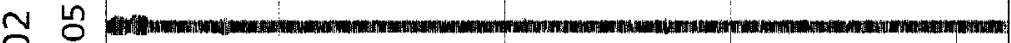

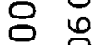

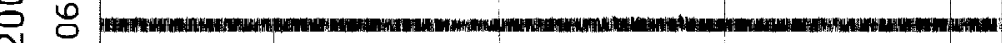

N

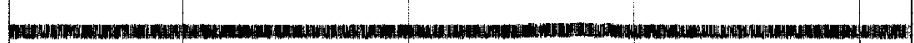

$=$

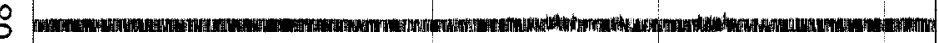

$\leftarrow$ o

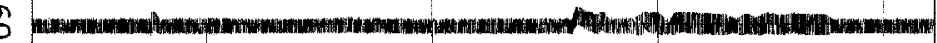

ㄱ.

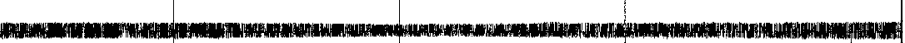

근.

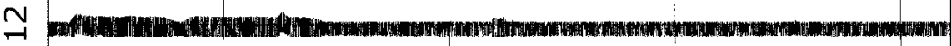

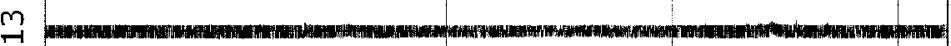

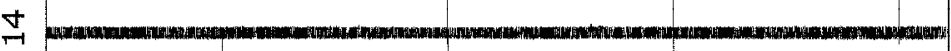

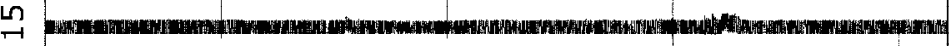

그.

ᄀ

$\underset{-1}{\infty}$ MIII

on

แaแrousua

\begin{tabular}{lllllllll}
\hline & 3 & 6 & 9 & 12 & 15 & 18 & 21 & 24
\end{tabular}

Time [LT] 
(b)

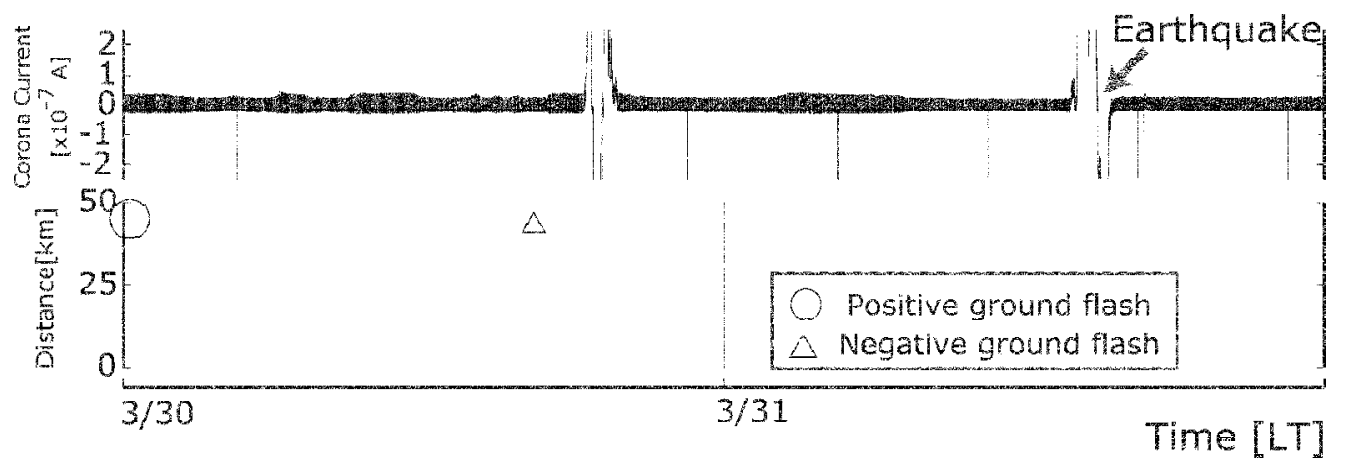

(c)

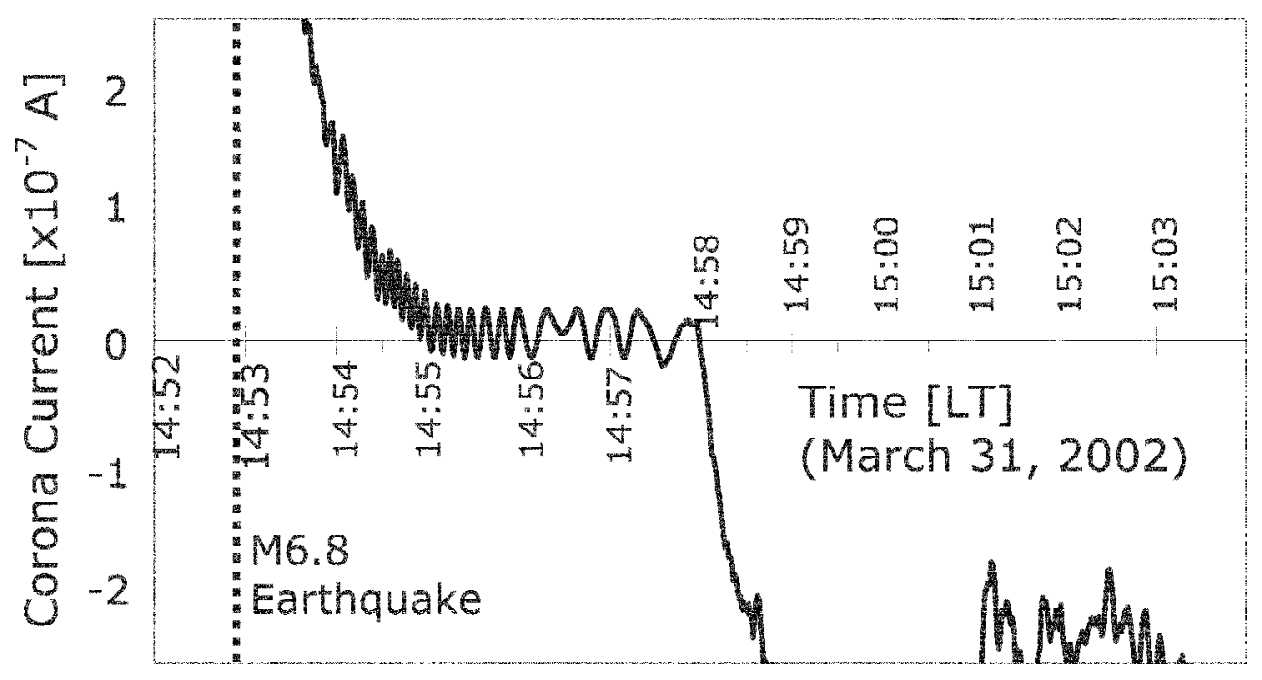

Fig. 6. Corona current data. The M6.8 earthquake occurred at 14:52 (LT) on March 31, 2002. (a) Two weeks before and after the earthquakes (b) March 30 and 31 with time and distance of cloud-to-ground lightning strikes in the lower panel (c) Enlarged data at the time of the earthquake at 14:52 (LT) on March 31, 2002. 
(a)

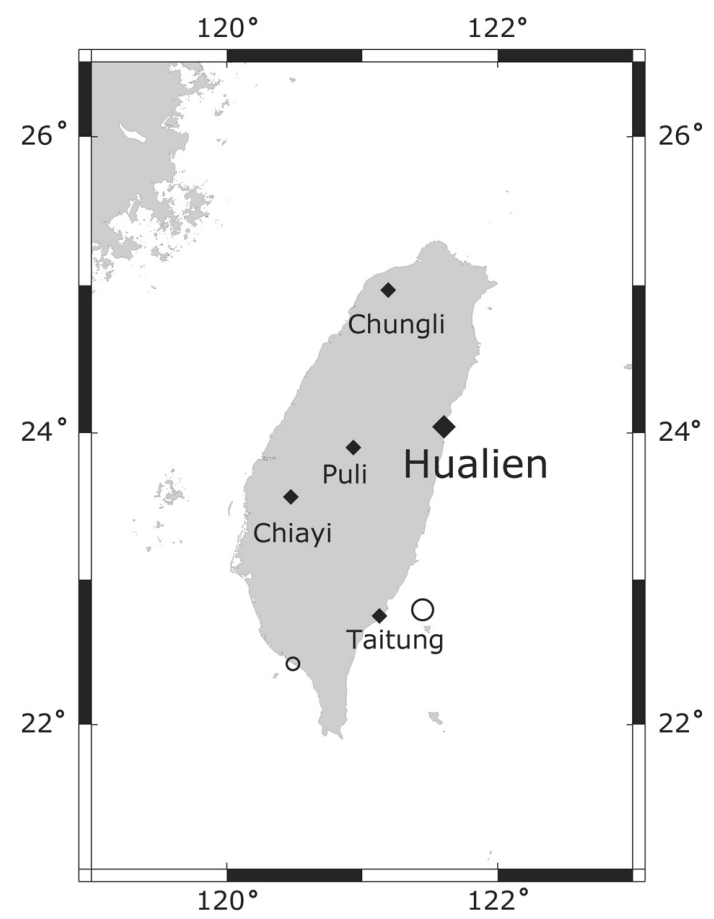

(c)

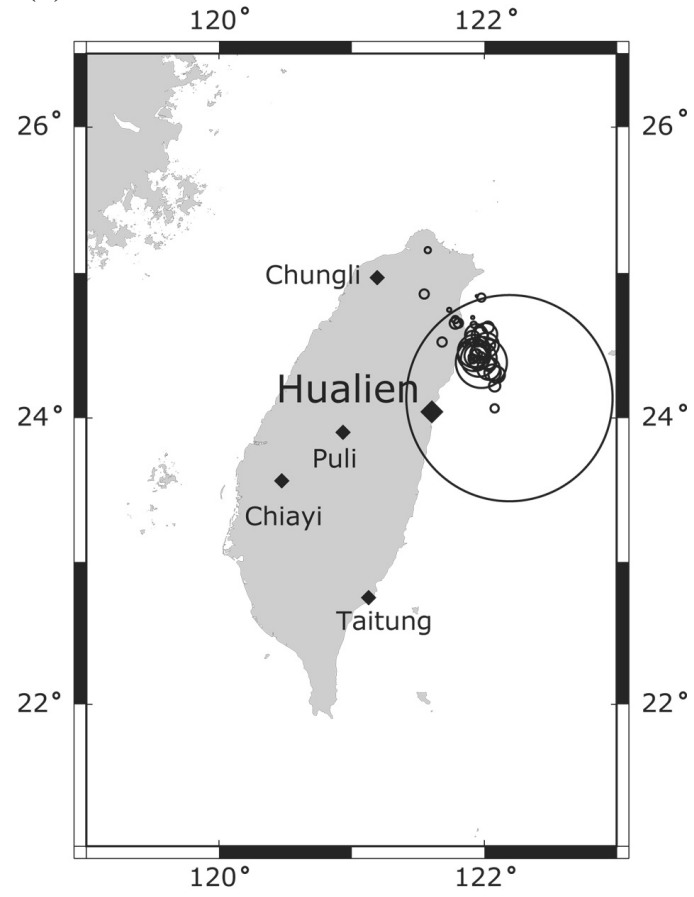

(b)

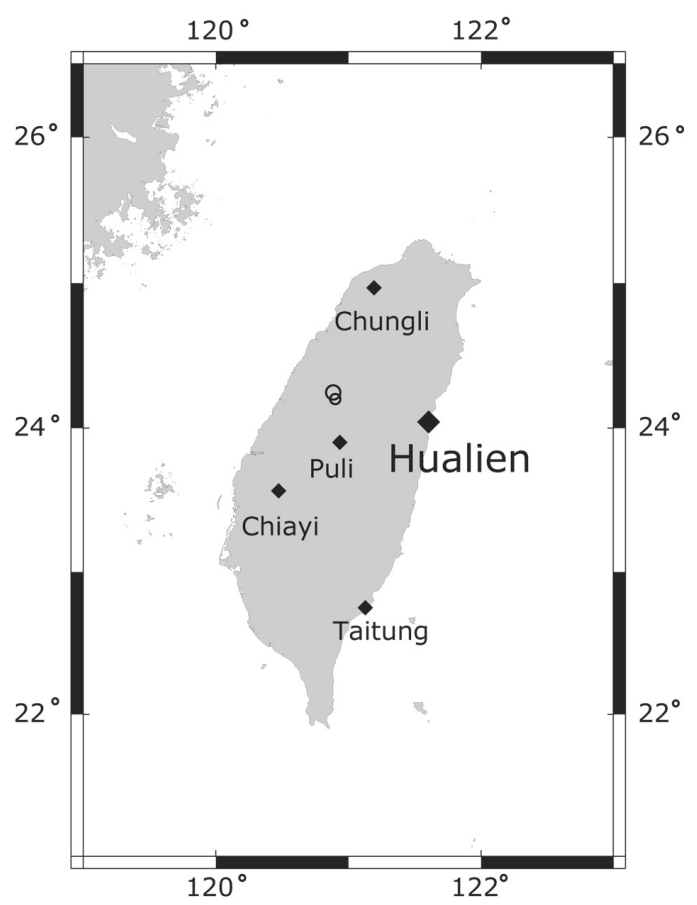

Fig. 7. Seismicity during the AFE variations (Central Weather Bureau) (a) From 18:26 to 19: 39 on March 30. (b) From 13: 53 to main shock on March 31. (c) From main shock to 15:27 on March 31. 


\subsection{ULF Magnetic Anomalies}

An ULF magnetic observation station has been in operation at Chiayi as shown in Fig. 2 containing a fluxgate magnetometer with 3 components operating at a $1 \mathrm{~Hz}$ sampling rate (Hattori et al. 2002a). The distance to the M6.8 earthquake epicenter is about $190 \mathrm{~km}$ as shown in Fig. 2. A polarization analysis has been performed by determining the spectral density ratio between the vertical and horizontal components, $S_{Z} / S_{G}$ (Hattori et al. 2002b, 2004a, 2004b). The result is described in Fig. 8. Figure 8a shows the seismic activity around the Chiayi station as defined by daily released seismic energy in terms of magnitude $M$. Figure $8 \mathrm{~b}$ plots the variation of the polarization in the $0.01 \mathrm{~Hz}$ band at midnight. The thin and bold lines indicate daily variations and the 5-day running mean values. Although there is a data gap around the day of the earthquake, no anomalous behavior seems to have occurred. According to the empirical experience shown in Fig. 9 (Hattori et al. 2004b), this epicentral distance was too large to detect ULF magnetic anomalies.

(a)

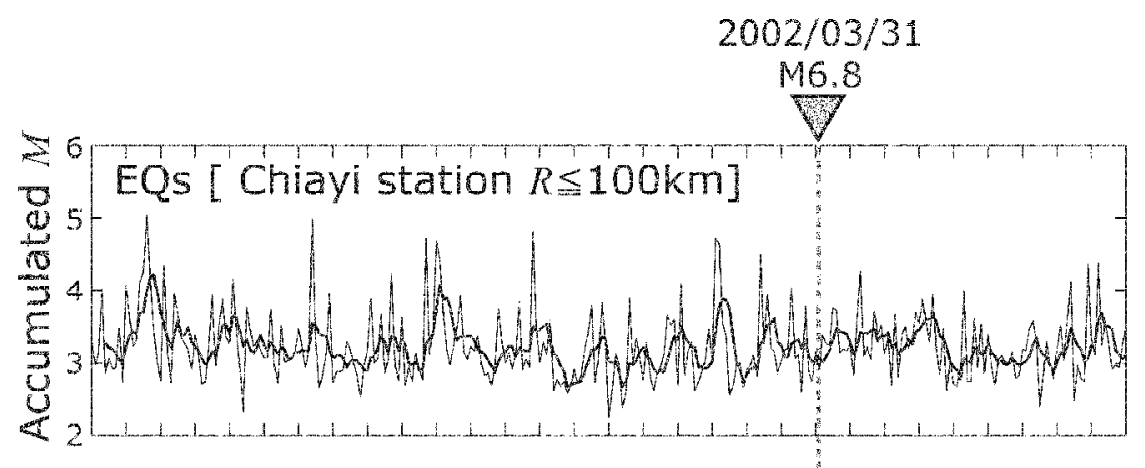

(b)

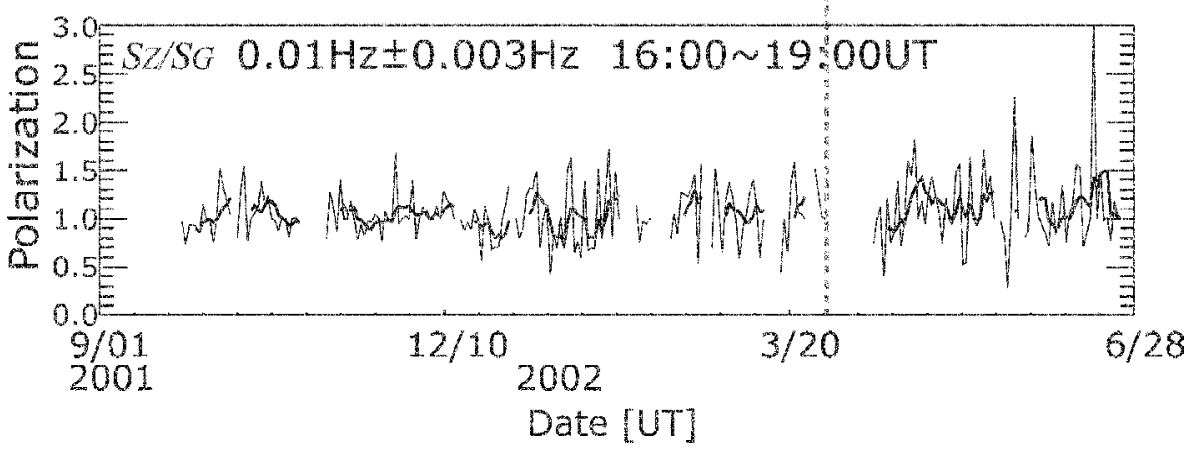

Fig. 8. The experimental results of ULF geomagnetic variations based on polarization approach. (a) The regional seismic activity in terms of magnitude $(M)$. Earthquakes within the epicenral distance of $100 \mathrm{~km}$ are collected and daily sum of energy is computed from the earthquake catalog (Central Weather Bureau). (b) The variation of polarization $\left(S_{Z} / S_{G}\right)$ in the range of $0.01 \mathrm{~Hz}$ at the Chiayi station. 


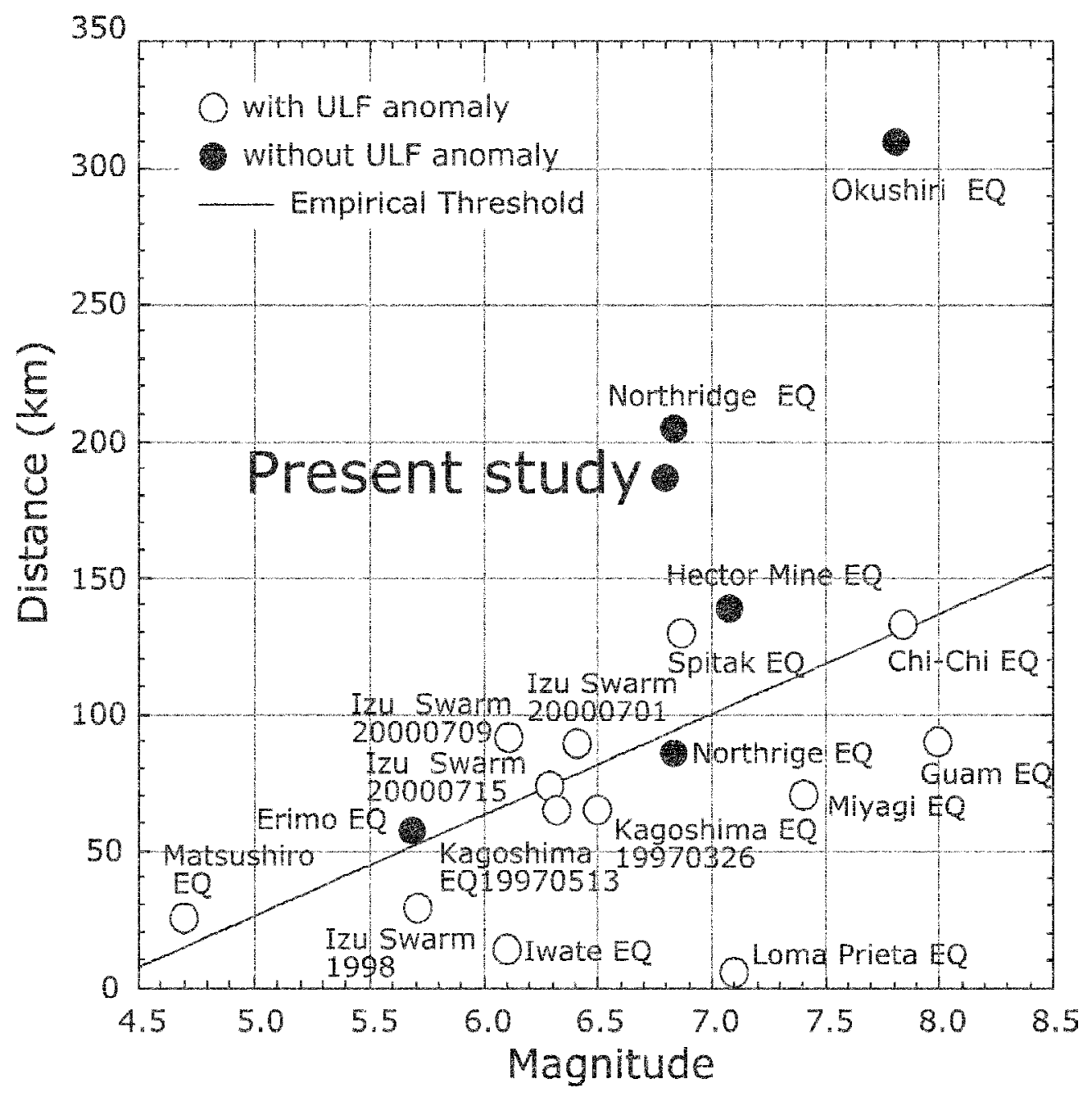

Fig. 9. Summary of ULF magnetic anomalies associated with large earthquakes. The empirical threshold is given by $0.025 \mathrm{R}=M-4.5$, where $R$ is the distance and $M$ the magnitude. The result of this study is also presented.

\subsection{Ionospheric Anomalies}

Ionospheric anomalies associated with earthquakes have been investigated since the 1980s. In particular, Liu et al. (2000) statistically showed that, prior to large earthquakes, the electron density as observed by an ionosonde decreased in the $\mathrm{F}_{2}$-layer. In the data obtained in Taiwan over a period of 6 years (1994 - 1999), the anomalies distinctly appeared within 6 days before 
$M \geq 6$ earthquakes. Furthermore, Liu et al. (2003) determined the total electron contents (TEC) in the ionosphere using global positioning system (GPS) data and applied these GPS-TEC observations to the study of the seismo- ionospheric anomalies. They arrived at the conclusion that ionospheric anomalies were present in $80 \%$ of $M \geq 6$ earthquakes in Taiwan during 3 years (1999 - 2001). In order to understand the physical mechanisms leading to seismo-ionospheric anomalies, two types of energy transmission channels through the atmosphere could be proposed as shown Fig. 10 such as "mechanical effects" and "electromagnetic effects" (See Gokhberg et al. 1995). Among the "electromagnetic effects", especially "electric field effects", it has been proposed that AEF variations could lead to ionospheric anomalies. In addition, there are some theoretical estimates based on this assumption (Gokhberg et al. 1995; Pulinets 1998; Grimalsky et al. 2003). There works showed that $1 \mathrm{kV} \mathrm{m}^{-1}$ was roughly required on the ground. Therefore, it is important to compare the AEF variations measured on the ground with suspected ionospheric anomalies before earthquakes. From equation (1) and the present observation condition, corona discharges require an ambient AEF in excess of approximately a few hundreds $\mathrm{V} \mathrm{m}^{-1}$. Based on these estimates, the present corona current measurements should be able to detect AFE variations that would cause the ionospheric anomalies.

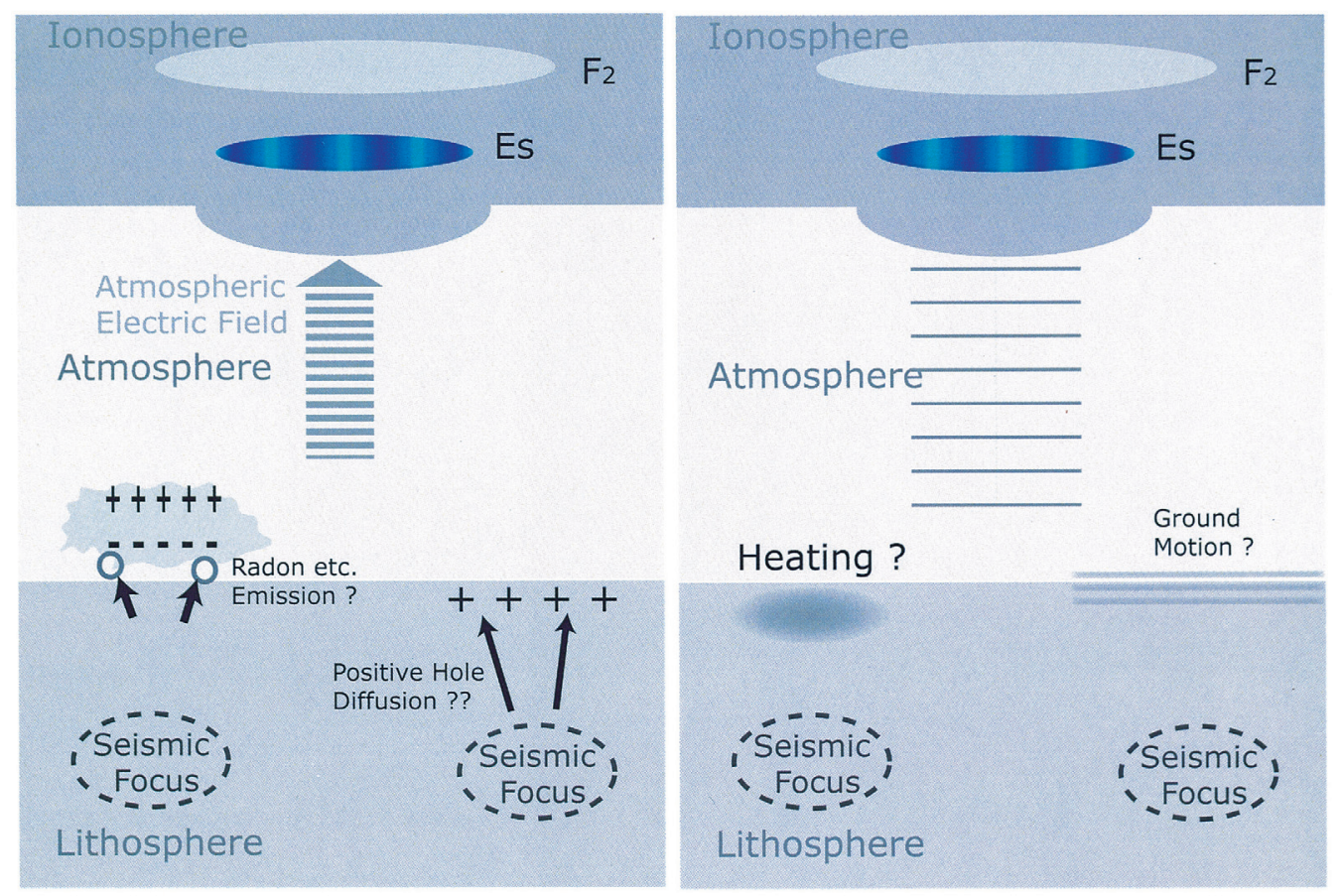

Fig. 10. Proposed mechanisms could be categorized as electric field effect and mechanical effect. 
According to the criteria defined by Liu et al. (2003), in the case of the March 31, 2002 observations, seismo-ionospheric anomalies also appeared before the $M 6.8$ earthquake as shown in Fig. 11. Two and four days before the main shock, vertical TEC values over Hualien decreased during the afternoon hours below the lower bound, marking the seismo-ionospheric anomalies. Although the AEF changed one day before and 45 minutes before the main shock (upper panel of Fig. 11), no detectable variation seems to have occurred two and four days before. Therefore, in the case of this particular earthquake, there is no evidence to support the proposed channels.

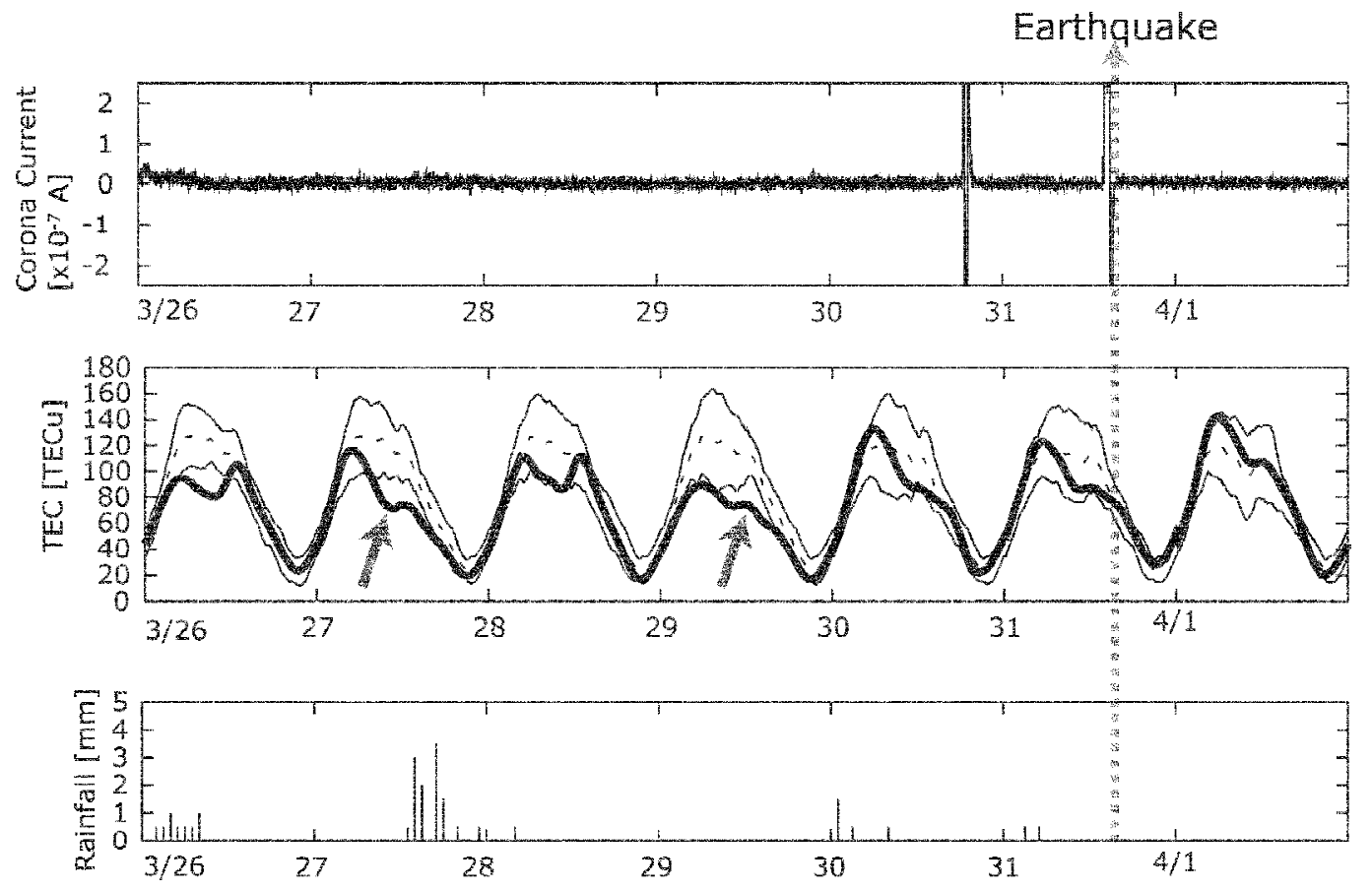

Fig. 11. TEC data. In the present study, the ionospheric anomalies were detected by the same method reported by Liu et al. (2003). They let the upper and lower bounds (UB and LB) be $\tilde{X}+I Q R$ and $\tilde{X}-I Q R$, where $\tilde{X}$ and $I Q R$ are the previous 15-day running median value at each time and the associated inter-quartile range (= first quartile - third quartile), respectively. According to their criteria, seismo- ionospheric anomalies were detected when the TEC values fell below the lower bound during afternoon hours and no magnetic storm occurred within 5 days before the earthquakes. Therefore, it can be said that seismo- ionospheric anomalies appeared two and four days before the $M 6.8$ earthquake. 


\section{CONCLUSION}

AEF observations, based on corona current measurements, have been performed in Taiwan in the context of seismo-electromagnetic studies. AEF variations might have appeared before the largest $M 6.8$ earthquake during the 3-year observation period, possibly representing the first report of a seismo-AEF correlation. On the other hand, while measurable seismoionospheric anomalies also occurred 2 and 4 days before the main shock, no evidence was found that these ionospheric anomalies were associated with the atmospheric electric field variation measured on the ground. Although the present study is based on only one case, future statistical studies, which include a larger number of earthquakes, may allow us to develop the criteria for seismo-AEF anomalies.

Acknowledgements The authors would like to thank Mr. G. Kato, Mr. Noma, and Dr. N. Kitagawa (Central Lightning Protection Co. Inc., Japan) for their great supports. The authors also wish to express the gratitude to Mr. S. W. Chen (National Central University, Taiwan), Prof. C. F. Shieh, Mr. C. L. Chien (National Chung-Cheng University, Taiwan), Prof. Y. L. Wu (National Chi-Nan University, Taiwan), Prof. Louis K. Chang, Mr. Ted Chen, Ms. M. H. Yau (Dahan Institute of Technology, Taiwan), and Prof. Y. S. Pan (National Tai-Tung University, Taiwan) to keep the well-running of the observation stations. The authors would like to thank Prof. H. Ofuruton (Tokyo Metropolitan College of Aeronautical Engineering), Mr. M. Ikeda (Sinteck Co. Inc., Japan), Mr. S. Muramatsu (Sanai Co. Inc., Japan) for their assistance, comments and comprehension of our projects. This project was partially supported by Grants-in-Aid for Scientific Research of Ministry of Education, Culture, Sports, Science and Technology in Japan (Grant number: 11878072), RIKEN International Frontier Research on Earthquakes, and Waseda University (Grant number: 2000A-863, 2001A-587), and iSTEP project in Taiwan.

\section{REFERENCES}

Chalmers, J. A., 1967: Atmospheric Electricity. Pergamon Press, Oxford. 250p.

Freund, F., 1999: Time-resolved study of charge generation and propagation in igneous rocks, J. Geophys. Res., 5, 11001-11020.

Gokhberg, M. B., V. A. Morgounov, and O. A. Pokhotelov, 1995: Earthquake Prediction: Seismo-Electromagnetic Phenomena. Taylor \& Francis.

Grimalsky, V. V., M. Hayakawa, V. N. Ivchenko, Y. G. Rapoport, and V. I. Zadorozhnni, 2003: Penetration of an electrostatic field from the lithosphere into the ionosphere and its effect on the D-region before earthquakes. J. Atmos. Solar-Terr. Phys., 65, 391-407.

Hattori, K., I. Takahashi, C. Yoshino, T. Nagao, J. Y. Liu, and C. F. Shieh, 2002a: ULF Geomagnetic and Geopotential Measurement at Chia-Yi, Taiwan.J. Atmos. Electricity, 22, 217-222. 
Hattori, K., Y. Akinaga, M. Hayakawa, K. Yumoto, T. Nagao, and S. Uyeda, 2002b: ULF magnetic anomaly preceding the 1997 Kagoshima Earthquakes, Seismo Electromagnetics: In: Hayakawa M., and O. A. Molchanov (Eds.), Lithosphere-Atmosphere-Ionosphere coupling, TERRAPUB, Tokyo, 19-28.

Hattori, K., I. Takahashi, C. Yoshino, N. Isezaki, H. Iwasaki, M. Harada, K. Kawabata, E. Kopytenko, Y. Kopytenko, P. Maltsev, V. Korepanov, O. Molchanov, M. Hayakawa, Y. Noda, T. Nagao, and S. Uyeda, 2004a: ULF geomagnetic field measurements in Japan and some recent results associated with Iwateken Nairiku Hokubu Earthquake in 1998. Phys. and Chem. Earth, 29, 481-494.

Hattori, K., 2004b: ULF geomagnetic changes associated with large earthquakes, ibid.

Ikeya, M., T. Matsuda, and C. Yamanaka, 1998: Reproduction of mimosa and clock anomalies before earthquakes: Are they Alice in Wonderland Syndrome? Proc. Japan Acad., 74, Ser. B, 60-64.

Ikeya, M., and H. Matsumoto, 1997: Reproduced earthquake precursor legends using a Van de Graaff electrostatic generator, Candle flame and dropped nails. Naturwissenschaften, 84, 539-541.

Kitagawa, N., and G. Katoh, 1995: Lightning warning device with complex seasons and its performance for actual thunderstorms. J. Atmos. Electricity., 15, 11-20.

Kondo, G., 1968: The variation of the atmospheric field at the time of earthquake. Mem. Kakioka Magnetic Observatory, 13, 11-23.

Liu, J. Y., Y. I. Chen, Y. J. Chuo, and H. F. Tsai, 2001: Variations of ionospheric total electron content during the Chi-Chi earthquake. Geophys. Res. Lett., 28, 1383-1386.

Liu, J. Y., Y. I. Chen, S. A. Pulinets, Y. B. Tsai, and Y. J. Chuo, 2000: Seismo-ionospheric signatures prior to $\mathrm{M} \geq 6.0$ Taiwan earthquakes. Geophys. Res. Lett., 27, 3113-3116.

Liu, J. Y., Y. J. Chuo, S. J. Shan, Y. B. Tsai, S. A. Pulinets, and S. B. Yu, 2003: Pre-earthquake ionospheric anomalies registered by continuous GPS TEC.Annales Geophysicae, 22, 1-9.

Macgorman, D. R, and W. D. Rust, 1998: The Electrical Nature of Storms. Oxford University Press, London.

Pulinets, S. A., 1998: Seismic activity as a source of ionospheric variability. Adv. Space Res., 22, 903-906. 